\title{
Low-intensity vibrations normalize adipogenesis-induced morphological and molecular changes of adult mesenchymal stem cells
}

Proc IMechE Part $\mathrm{H}$ :

$\mathrm{J}$ Engineering in Medicine

2017, Vol. 23I(2) 160-168

(c) IMechE 2017

Reprints and permissions:

sagepub.co.uk/journalsPermissions.nav DOI: $10.1177 / 0954411916687338$

journals.sagepub.com/home/pih

(S)AGE

\author{
Oznur Baskan', Gulistan Mese ${ }^{2}$ and Engin Ozcivici'
}

\begin{abstract}
Bone marrow mesenchymal stem cells that are committed to adipogenesis were exposed daily to high-frequency lowintensity mechanical vibrations to understand molecular, morphological and ultrastructural adaptations to mechanical signals during adipogenesis. DI-ORL-UVA mouse bone marrow mesenchymal stem cells were cultured with either growth or adipogenic medium for I week. Low-intensity vibration signals ( $15 \mathrm{~min} / \mathrm{day}, 90 \mathrm{~Hz}, 0.1 \mathrm{~g}$ ) were applied to one group of adipogenic cells, while the other adipogenic group served as a sham control. Cellular viability, lipid accumulation, ultrastructure and morphology were determined with MTT, Oil-Red-O staining, phalloidin staining and atomic force microscopy. Semiquantitative reverse transcription polymerase chain reaction showed expression profile of the genes responsible for adipogenesis and ultrastructure of cells. Low-intensity vibration signals increased viability of the cells in adipogenic culture that was reduced significantly compared to quiescent controls. Low-intensity vibration signals also normalized the effects of adipogenic condition on cell morphology, including area, perimeter, circularization and actin cytoskeleton. Furthermore, low-intensity vibration signals reduced the expression of some adipogenic markers significantly. Mesenchymal stem cells are sensitive and responsive to mechanical loads, but debilitating conditions such as aging or obesity may steer mesenchymal stem cells toward adipogenesis. Here, daily application of low-intensity vibration signals partially neutralized the effects of adipogenic induction on mesenchymal stem cells, suggesting that these signals may provide an alternative and/or complementary option to reduce fat deposition.
\end{abstract}

\section{Keywords}

Mesenchymal stem cells, vibrations, in vitro cell culture, mechanical signals, adipogenic commitment, bone marrow

\section{Introduction}

Obesity is a multifactorial disease that leads to serious health problems such as type 2 diabetes, cardiovascular and cerebrovascular diseases, hypertension, digestive disorders and cancer. The number of deaths declared by the World Health Report shows the severity of the problem which indicates that more than 2.5 million of deaths worldwide per year are weight related. ${ }^{1}$ Increased fat content in adipose tissue is the hallmark of obesity ${ }^{2}$ and that increase is related to genetic factors ${ }^{3}$ as well as poor diet $^{4}$ and sedentary lifestyles. ${ }^{5}$ Even though fat accumulation occurs mainly in subcutaneous and visceral adipose tissues, ${ }^{6}$ bone marrow space is also affected and filled with adipocytes during obesity. ${ }^{7}$

The bone marrow fat is originated from adult mesenchymal stem cells, ${ }^{8}$ and even progenitor cells that are committed to bone formation have the capability to form marrow adipocytes. ${ }^{9}$ Studies show that obesity inducing factors, such as high fat diet ${ }^{10,11}$ or leptin deficiency, ${ }^{12}$ may disturb bone marrow mesenchymal stem cell population, increase bone marrow fat and be detrimental to bone structure. These observations are supported by clinical evidence that an inverse relationship exists between bone marrow fat and bone mass. ${ }^{13-15}$ Bone marrow fat may be a serious threat to bone

\footnotetext{
'Department of Bioengineering, Izmir Institute of Technology, Izmir Turkey

${ }^{2}$ Department of Molecular Biology and Genetics, Izmir Institute of Technology, Izmir, Turkey
}

\section{Corresponding author:}

Engin Ozcivici, Department of Bioengineering, Izmir Institute of Technology, Rm A208, Urla, Izmir 35430, Turkey.

Email: enginozcivici@iyte.edu.tr 
health, not only because adipocytes compete with the osteoblasts for the same stem cell pool, but also the bone marrow composition can become more adipogenic and pro-inflammatory during the progression of fat accumulation. ${ }^{16}$ Protection of bone marrow from adipogenesis may require strategies that directly affect stem cell population and steer commitment of those cells to osteogenesis from adipogenesis. ${ }^{17}$ Out of those strategies, efforts of daily mechanical intervention showed promising results in suppressing marrow adipogenesis during diet-induced obesity in mice. ${ }^{7}$ Suppressing marrow adipogenesis with a nonpharmaceutical strategy that also affects other organs and systems positively is plausible, yet the information on which constituents of a mechanical signal is sensed and responded by bone marrow stem cells is still limited. ${ }^{18,19}$

Bone cells sense and respond to different forms of mechanical loads, including cyclic stretch, ${ }^{20}$ static pressure, $^{21}$ shear stress ${ }^{22,23}$ and nanoscale mechanotransduction. ${ }^{24,25}$ In addition to these loading variants, daily application of low-intensity $\left(<0.5 \mathrm{~g}, 1 \mathrm{~g}=9.81 \mathrm{~m} / \mathrm{s}^{2}\right)$ vibrations (LIVs) in high frequencies $(>30 \mathrm{~Hz})$ is anabolic to bone tissue and can suppress obesity in murine and clinical studies. ${ }^{26-28}$ LIV can also help maintaining a healthy bone marrow during conditions that are detrimental to bone marrow, such as mechanical disuse ${ }^{29}$ or diet-induced obesity. ${ }^{30}$ On cellular level, LIV acts as pro-osteogenic to bone marrow stem cells and influences their proliferation, morphology, cell-to-cell communication and molecular markers in vitro ${ }^{31-33}$ but cells of other developmental origins, such as epithelial cells, appear to be less sensitive to LIV signals. $^{34}$ Furthermore, in vitro application of LIV signals during adipogenesis inhibit lipid accumulation. ${ }^{35}$

Application of LIV in vitro induces a broad range of cellular and molecular responses to osteoprogenitor cells, ${ }^{36,37}$ however these responses are less known for stem cells that are committed to adipogenesis. Here, we subjected D1-ORL-UVA mouse bone marrow stem cells daily to LIV signals during induced adipogenesis to document isolated cellular adaptation of stem cells on morphological, ultrastructural and molecular level.

\section{Materials and methods}

\section{Cell culture}

Mouse bone marrow pluripotent stem cell line D1-ORL-UVA (American Type Culture Collection, USA) that is able to differentiate into all mesenchymal cell types including adipocytes was used in all experiments. D1-ORL-UVA cells were grown and maintained in Dulbecco's Modified Eagles Medium (DMEM; Thermo Scientific HyClone, USA) supplemented with $10 \%$ fetal bovine serum (Biological Industries, Israel) and $1 \%$ penicillin/streptomycin (Biological Industries, Israel) as instructed by the vendor. For all experiments, D1-ORL-UVA cells were used between passages 6 and 12. Adipogenic induction is achieved by addition of $5 \mu \mathrm{g} / \mathrm{mL}$ of insulin (Sigma, USA), $50 \mu \mathrm{M}$ of indomethacin (Sigma, USA) and $10 \mathrm{nM}$ of dexamethasone (Sigma, USA) to the growth medium, which can induce lipid accumulation. For all experiments except atomic force microscopy (AFM) and reverse transcription polymerase chain reaction (RT-PCR), D1-ORL-UVA cells were plated at a density of 500 cells/well in 24-well plates (Corning, USA) for individual cell morphology analysis and maintained in the growth medium at $37^{\circ} \mathrm{C}$ and $5 \% \mathrm{CO}_{2}$. Plated cell number was selected based on the criteria that at the end of experiment, cells would reach to $80 \%-90 \%$ confluency. For AFM experiments, $8 \times 10^{4}$ cells were grown on $10 \mathrm{~cm}$ plates and $5 \times 10^{3}$ cells were grown on 6-well plates for RT-PCR experiments. During experiments, cells were first allowed to adhere to the culture plate for 2 days and then media was either refreshed (for quiescence) or changed with adipogenic media (for adipogenesis). Culture media was changed every 3 days and all experiments were terminated at day 9 for morphology, lipid content, mRNA expressions and AFM. Some cultures were continued to assess osteogenic potential of D1-ORL-UVA cells after adipogenic induction. For those experiments, osteogenic supplements $(1000 \mu \mathrm{g} / \mathrm{mL}$ ascorbic acid and $10 \mathrm{mM} \beta$-glycerol phosphate; Sigma, USA) were used to replace adipogenic supplements. These follow-up experiments were either continued for 1 week for mRNA expression or 2 weeks for micrographs of lipid and calcium phosphate accumulation.

\section{Mechanical stimulation}

Cells were either subjected to $90 \mathrm{~Hz}, 0.15 \mathrm{~g}$ vibrations for 7 days $(15 \mathrm{~min} /$ day) under room conditions or received sham treatment to eliminate the effects of ambient conditions. ${ }^{31,34}$ Briefly, proper sinusoidal signals were generated via a custom-made platform (Figure 1) and the brevity of this mechanical signal was continuously monitored with a real-time accelerometer (K-Beam; Kistler, USA) through LabVIEW 2010 Signal Express software (National Instruments, USA). D1-ORL-UVA cells that were kept in the growth media and received daily sham loading were reported as Growth Control (GC). D1-ORL-UVA cells that were cultured in adipogenic media that received daily loading were reported as Adipogenic Vibration (AV), while adipogenic D1-ORL-UVA cells that received sham loading were reported as Adipogenic Control (AC). To understand long-term osteogenic potential, after 9 days, GC, AC and AV groups were continuously cultured in osteogenic media (GCO-Growth Control followed by osteogenic induction, ACOAdipogenic Control followed by osteogenic induction and AVO-Adipogenic Vibration followed by osteogenic induction). 


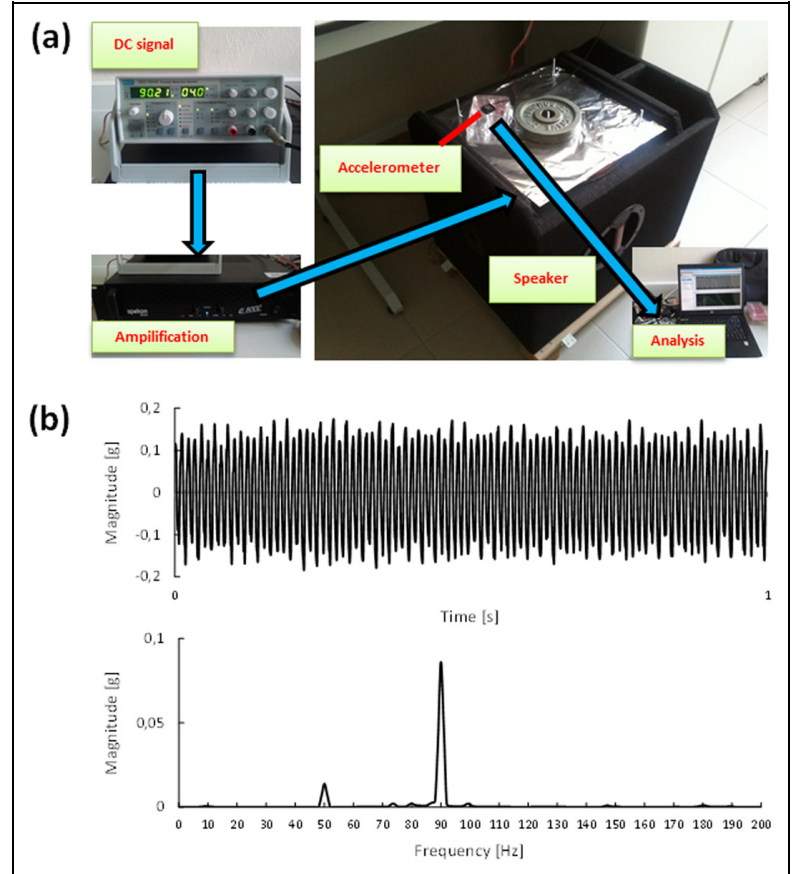

Figure I. Mechanical stimulation applied to the cells at $90 \mathrm{~Hz}$ and $0.15 \mathrm{~g}$ for the study: (a) components of the mechanical vibration delivery platform and (b) representative data from time and frequency domains. Note that the small peak in $50 \mathrm{~Hz}$ corresponds to the electromagnetic noise from the power grid.

\section{Cell growth and viability}

At day 9, cell viability was analyzed via MTT (3-(4,5dimethylthiazol-2-yl)-2,5-diphenyltetrazolium bromide) assay, in which cells were incubated with $0.5 \mathrm{mg} / \mathrm{mL}$ MTT (AMRESCO LLC, USA) for $4 \mathrm{~h}$. After the incubation, tetrazolium salts were dissolved in $600 \mu \mathrm{L}$ dimethyl sulfoxide (DMSO) for $2 \mathrm{~min}$ and colorimetric measurements were done at $570 \mathrm{~nm}$ with a background subtraction at $650 \mathrm{~nm}$.

\section{Immunostaining and fluorescent microscopy}

Cells were washed with phosphate buffered saline (PBS) and fixed with 4\% paraformaldehyde (PFA) for 20 min. PFA was triple washed with PBS followed by membrane permeabilization with $0.1 \%$ Triton $\mathrm{X} / \mathrm{PBS}$ for $15 \mathrm{~min}$. Cells were blocked with $3 \%$ bovine serum albumin (BSA) in $0.1 \%$ Triton $\mathrm{X} / \mathrm{PBS}$ for $30 \mathrm{~min}$ and were then incubated with Alexa488-conjugated phalloidin (Invitrogen, USA) for $30 \mathrm{~min}$ in the dark for the imaging of actin filaments. After gentle washing with PBS, cells were incubated in 4',6-diamidino-2-phenylindole (DAPI) solution for visualization of nuclei. Images were acquired with an inverted microscope and fluorescent attachment (CKX71; Olympus, Japan). A minimum of 10 sample images were used for signal intensity measurement per condition from three different experiments. Images were analyzed using ImageJ software. Lipid content of cells was determined with Oil-Red-O staining, while calcium phosphate accumulation was determined with alizarin red stains.

\section{AFM}

Nanosurf FlexAFM (Nanosurf, Switzerland) was used to get AFM images. Cells were probed with NonContact/Tapping Mode-Long Cantilever-Reflex Coating (NCLR) tip with $190 \mathrm{kHz}$ resonance frequency and $48 \mathrm{~N} / \mathrm{m}$ force constant in DMEM. Scans were conducted with $71.4143 \mathrm{kHz}$ vibration frequency and $3.07 \mathrm{mV}$ vibration amplitude. Cells were analyzed for average surface roughness ( $\mathrm{Ra})$, root-mean-square roughness $(\mathrm{Rq})$, maximum height $(\mathrm{Ry})$, maximum peak height (Rp) and maximum valley depth (Rv) using AFM image processing software Nanosurf Scan.

\section{Gene expression analysis}

Cells were lysed and total mRNA was isolated using PureLink RNA mini kit (Invitrogen, USA). After verification of purity and determination of concentration with NanoDrop (ND-1000; Thermo Scientific, USA), two-step real-time PCR was performed. For reverse transcription reaction, RevertAid first strand cDNA synthesis kit (Thermo Scientific, USA) was used with $1000 \mathrm{ng}$ template RNA. cDNA samples of $7.5 \mu \mathrm{L}$ were loaded with $12 \mu \mathrm{L}$ of Sybr Green (Thermo Scientific, USA), $2.5 \mu \mathrm{L}$ forward and reverse primers of adipogenic, osteogenic markers and cytoskeletal molecules for semiquantitative RT-PCR (Bio-Rad, USA), where GAPDH (glyceraldehyde 3-phosphate dehydrogenase) was used as the house-keeping molecule (Table 1). For all groups, 3-4 samples were used for gene expression analysis.

\section{Statistical analysis}

All results were expressed as mean ( \pm standard deviation). Group comparisons were done using unpaired t-tests between growth and adipogenic as well as control and vibration groups, in which the threshold for statistical significance was set to $5 \%$.

\section{Results}

\section{Adipogenic induction and cell viability}

Adipogenic induction resulted in positive Oil-Red-O signal showing the lipid accumulation in D1-ORLUVA cells at the end of first week, while stem cells that remained in growth media did not show any signal (Figure 2(a) and (b)). Cells that received mechanical vibrations showed lipid accumulation to a lesser extent (Figure 2(c)). Viability of AC cells was $28 \%(\mathrm{p}<0.01)$ smaller compared to GC cells. Daily application of LIV signal increased observed viability in AV group by $45 \%(\mathrm{p}<0.01)$ compared to AC cells (Figure 3$)$. 
Table I. Primers designed for the gene expression analysis of cytoskeletal elements, adipogenic and osteogenic markers for DIORL-UVA mouse mesenchymal stem cells. GAPDH (glyceraldehyde 3-phosphate dehydrogenase) was used as the house-keeping molecule for all groups.

\begin{tabular}{|c|c|c|}
\hline Gene & Direction & Sequence \\
\hline$\beta$-Actin & $\begin{array}{l}F \\
R\end{array}$ & $\begin{array}{l}\text { CTT CTT TGC AGC TCC TTC GTT } \\
\text { TTC TGA CCC ATT CCC ACC A }\end{array}$ \\
\hline Desmin & $\begin{array}{l}F \\
R\end{array}$ & $\begin{array}{l}\text { GTG AAG ATG GCC TTG GAT GT } \\
\text { GTA GCC TCG CTG ACA ACC TC }\end{array}$ \\
\hline Vimentin & $\begin{array}{l}F \\
R\end{array}$ & $\begin{array}{l}\text { ACG GTT GAG ACC AGA GAT GG } \\
\text { CGT CTT TTG GGG TGT CAG TT }\end{array}$ \\
\hline Lamin & $\begin{array}{l}\mathrm{F} \\
\mathrm{R}\end{array}$ & $\begin{array}{l}\text { ATC AAC TCC ACT GGA GAA GAA GT } \\
\text { CAG ACA GGA GGT GGC ATG T }\end{array}$ \\
\hline Collagen Ia & $\begin{array}{l}\mathrm{F} \\
\mathrm{R}\end{array}$ & $\begin{array}{l}\text { CAC CCT CAA GAG CCT GAG TC } \\
\text { AGA CCG CTG AGT AGG GAA CA }\end{array}$ \\
\hline$\beta$-catenin & $\begin{array}{l}\mathrm{F} \\
\mathrm{R}\end{array}$ & $\begin{array}{l}\text { AAG GAA GCT TCC AGA CAT GC } \\
\text { GCT TGC TCT CTT GAT TGC C }\end{array}$ \\
\hline Osteocalcin & $\begin{array}{l}\mathrm{F} \\
\mathrm{R}\end{array}$ & $\begin{array}{l}\text { CTG ACA AAG CCT TCA TGT CCA A } \\
\text { GCG CCG GAG TCT GTT CAC TA }\end{array}$ \\
\hline Adipsin & $\begin{array}{l}\mathrm{F} \\
\mathrm{R}\end{array}$ & $\begin{array}{l}\text { GCT ATC CCA GAA TGC CTC GTT } \\
\text { CCA CTT CTT TGT CCT CGT ATT GC }\end{array}$ \\
\hline Resistin & $\begin{array}{l}\mathrm{F} \\
\mathrm{R}\end{array}$ & $\begin{array}{l}\text { CAA CTC CCT GTT TCC AAA TGC } \\
\text { CTC AAG ACT GCT GTG CCT TCT }\end{array}$ \\
\hline C/EBP- $\alpha$ & $\begin{array}{l}\mathrm{F} \\
\mathrm{R}\end{array}$ & $\begin{array}{l}\text { TGG ACA AGA ACA GCA ACG AGT AC } \\
\text { GCA GTT GCC CAT GGC CTT GAC }\end{array}$ \\
\hline ENC-I & $\begin{array}{l}\mathrm{F} \\
\mathrm{R}\end{array}$ & $\begin{array}{l}\text { AAG CTT CGG CAT A } \\
\text { AAG } \mathrm{CT}_{\|,} \mathrm{A}\end{array}$ \\
\hline PPAR $\gamma$ & $\begin{array}{l}\mathrm{F} \\
\mathrm{R}\end{array}$ & $\begin{array}{l}\text { GCC TTG CTG TGG GGA TGT C } \\
\text { TCCTTGGCCCTCTGAGATGAG }\end{array}$ \\
\hline PTK2 & $\begin{array}{l}\mathrm{F} \\
\mathrm{R}\end{array}$ & $\begin{array}{l}\text { TTG GAC CTG GCA TCT TTG AT } \\
\text { AGA ACA TTC CGA GCA GCA AT }\end{array}$ \\
\hline GAPDH & $\begin{array}{l}\mathrm{F} \\
\mathrm{R}\end{array}$ & $\begin{array}{l}\text { GAC ATG CCG CCT GGA GAA AC } \\
\text { AGC CCA GGA TGC CCT TTA GT }\end{array}$ \\
\hline
\end{tabular}

\section{Cell morphology and AFM}

Morphological and ultrastructural differences induced by adipogenesis and daily application of LIV were quantified by single-cell analysis. Adipogenic induction reduced cellular area by $39 \%(\mathrm{p}<0.01)$ compared to GC cells (Figure 4(a)). LIV-applied AV cells showed $18 \%(\mathrm{p}=0.05)$ larger area compared to AC cells. Similarly, cellular perimeter was reduced by $42 \%$ $(\mathrm{p}<0.01)$ in AC group compared to GC group but vibrations increased AV cell perimeter by $20 \%$ ( $\mathrm{p}<0.01)$ compared to AC group (Figure 4(b)). Adipogenic conditions also increased the circularity of AC cells by $50 \%(\mathrm{p}<0.01)$ compared to $\mathrm{GC}$ group (Figure 4(c)). AV group had a 20\% $(\mathrm{p}<0.01)$ decrease in circularity compared to AC cells. Actin fluorescent signal per area was increased twofold $(\mathrm{p}<0.01)$ with adipogenic induction (Figure 4(d)). Mechanical vibrations reduced the actin signal in AV group $22 \%$ (p $<0.01)$ compared to AC cells.

Membrane probing for all groups using fluid-cell AFM showed that adipogenic induction reduced average membrane roughness of AC cells by $60 \%$ $(\mathrm{p}<0.05)$ but vibrations did not induce any change $(\mathrm{p}=0.4)$ in average roughness (Figure 5). Similarly, application of LIV signals did not change the Rq, Ry of cell surface, $\mathrm{Rv}$ of the cell surface roughness and $\mathrm{Rp}$ (Table 2).

\section{Gene expression}

Molecular changes in bone marrow stem cells during adipogenesis and vibrations were analyzed by semiquantitative RT-PCR (Figure 6). Results showed that neither adipogenesis nor vibration change the expression of ultrastructural molecule actin, desmin and lamin as well as $\beta$-catenin levels in D1-ORL-UVA cells. Vimentin level was decreased by $36 \%(\mathrm{p}<0.05)$ in AV group compared to AC cells. Adipogenic induction reduced the collagen level by $60 \%(p<0.05)$ compared to GC cells and AV cells showed a decline by $57 \%(\mathrm{p}<0.01)$ relative to $\mathrm{AC}$ cells. Adipogenic markers adipsin and resistin were increased in AC cells by 19 -fold and 214-fold (both $\mathrm{p}<0.05$ ), while vibration decreased the expression level of these genes by $59 \%$ and $94 \%$, respectively (both $\mathrm{p}<0.05$ ). Another adipogenic marker c-EBP $\alpha$ was increased by $55 \%(\mathrm{p}=0.05)$ in AC cells compared to GC cells, and its expression was normalized with vibration by $52 \%$ $(\mathrm{p}<0.05)$ in AV group. PPAR $\gamma$ which is another regulator of adipogenesis showed a 40\% $(\mathrm{p}<0.05)$ decrease in AV cells compared to AC cells. Moreover, expression level of ENC-1 gene was normalized and showed a closer level with GC cells via vibration by 2.5-fold increase in $\mathrm{AV}$ group compared to $\mathrm{AC}$ group $(\mathrm{p}=0.01)$. 


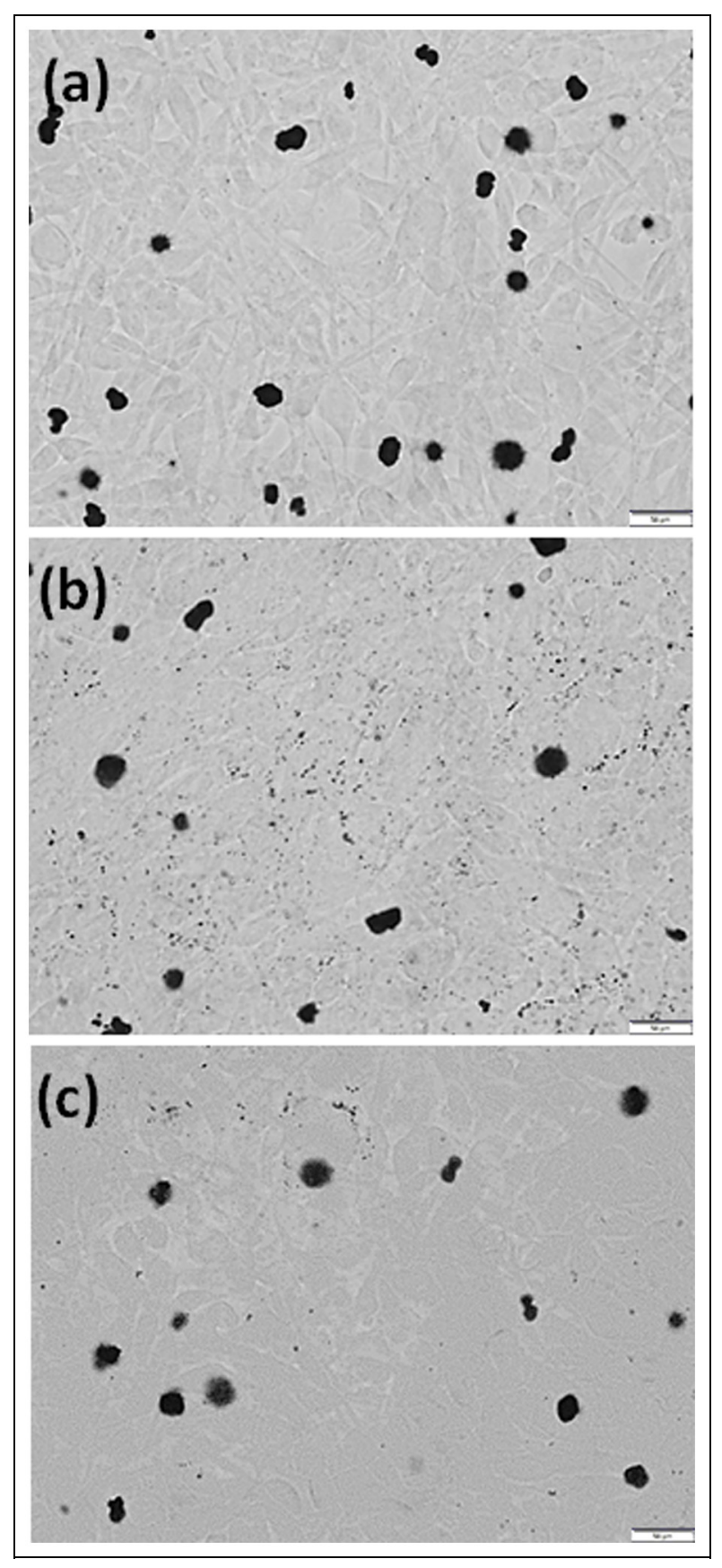

Figure 2. Light microscopy of Oil-Red-O stain (lipid accumulation) in DI-ORL-UVA cells after I week of culture in (a) growth media, (b) adipogenic media and (c) adipogenic media with daily application of mechanical vibrations.

\section{Osteogenic potential}

To test multipotency of D1-ORL-UVA cells after adipogenic induction, we replaced adipogenic supplements in the media with osteogenic supplements. Cells that did not receive adipogenic supplement earlier (GCO) were able to form clear mineral deposition after 2 weeks of osteogenic culture (Figure 7(a)). Adipogenic culture cells (ACO) were also able to form mineral deposits to a lesser extent once exposed to osteogenic conditions. Cells that received LIV during adipogenesis (AVO) showed larger accumulation of deposits during

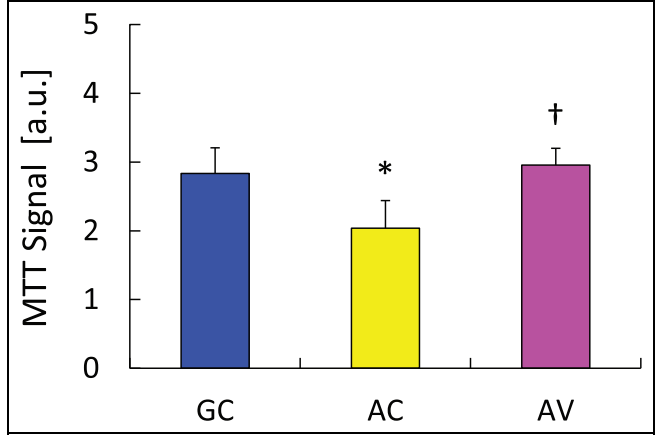

Figure 3. Viability of the cells as quantified by MTT assay. GC: Growth Control; AC: Adipogenic Control; AV: Adipogenic Vibration.

Results are presented as mean $\pm \mathrm{SD}$.

${ }^{*} \mathrm{P}<0.05$ between $\mathrm{GC}$ and $\mathrm{AC} ;{ }^{\dagger} \mathrm{P}<0.05$ between $\mathrm{AC}$ and $\mathrm{AV}$.

osteogenesis, even though LIV was discontinued on these cells during osteogenesis (Figure 7(a) and (c)). Furthermore, ACO cells still retained their lipid droplets after 2 weeks unlike AVO cells (Figure 7(c)). Osteocalcin, a molecular marker for osteogenesis was $65 \%(\mathrm{p}=0.02)$ larger in AVO cells compared to ACO (Figure 7(b)). PPAR $y$ of AVO cells on the other hand showed a trend $(-40 \%, p=0.15)$ in being smaller compared to ACO cells.

\section{Discussion}

Morphological and molecular effects of LIV on bone marrow mesenchymal stem cells during adipogenic commitment were investigated in this study. LIV signal was applied daily for $15 \mathrm{~min} /$ day in low magnitude $(0.15 \mathrm{~g})$ and high frequency $(90 \mathrm{~Hz})$ for 1 week. Results showed that adipogenesis-induced changes in morphological and molecular markers of stem cells were partially normalized with daily mechanical signals similar to quiescent controls. LIV application helped stem cells to retain their osteogenic potential better once the adipogenic environment was removed.

Inhibition of adipogenesis using mechanical signals in vitro was initially studied using low-frequency, highmagnitude signals, similar to those that are experienced during strenuous exercise. It was shown that application of cyclic mechanical stretching ${ }^{2}$ and uniform biaxial strain $^{38}$ reduced lipid accumulation in fibroblasts. Reduced lipid accumulation in fibroblasts was linked to the increased expression of $\beta$-catenin ${ }^{35}$ and suppression in PPAR $\gamma .{ }^{2}$ Observations on the suppressive effect of mechanical signals were also held with lower magnitude and higher frequency signal form, both in vivo ${ }^{26,27,39}$ and in vitro. ${ }^{2,38,40}$ Although our results did not indicate a drastic change in $\beta$-catenin levels and possible involvement of WNT pathway in D1-ORL-UVA cells, we observed that expression levels of various adipogenic markers were significantly reduced with the presence of LIV signals. Adipsin, ${ }^{41} \mathrm{c} / \mathrm{EBP}-\alpha^{42}$ and PPAR $\gamma^{43,44}$ are important adipocyte specific markers and significant 


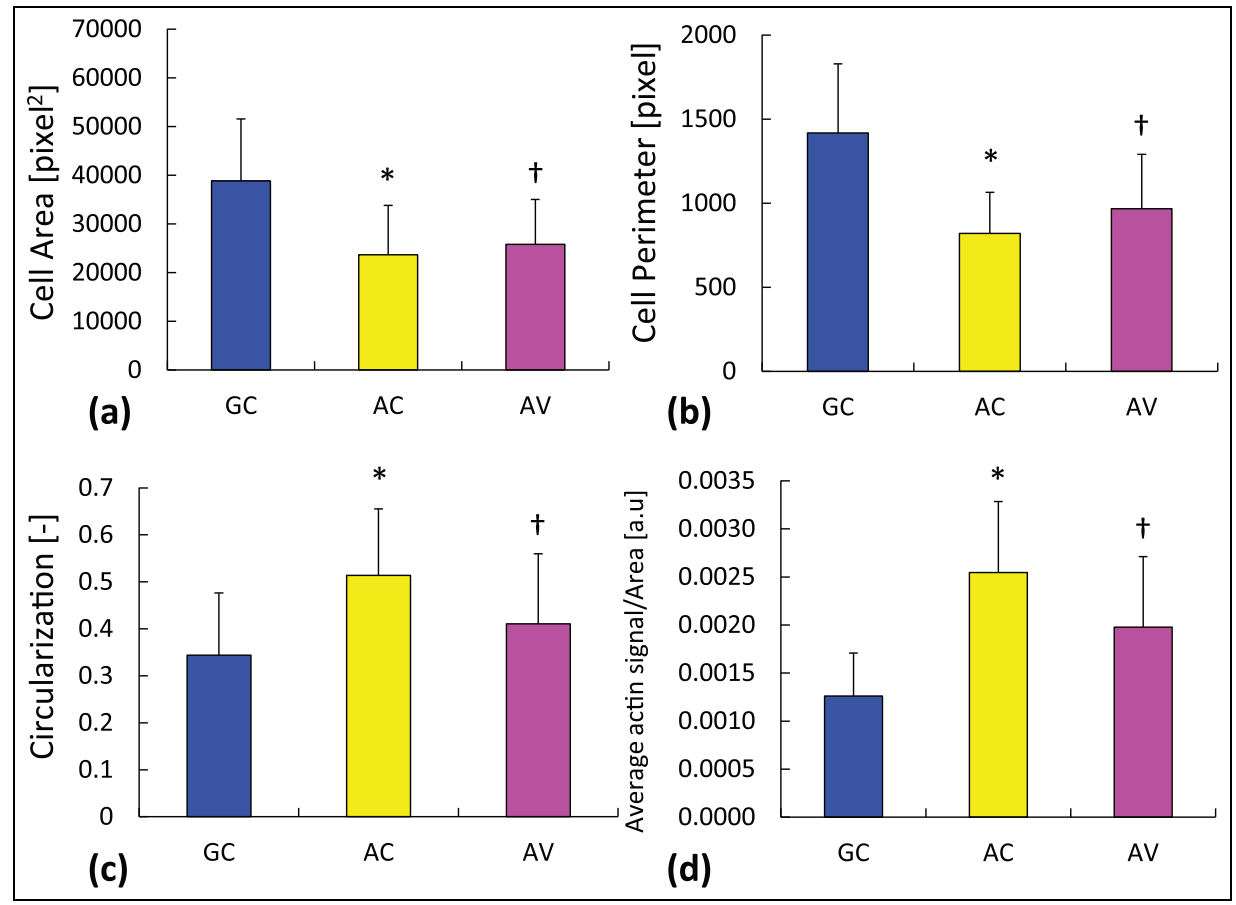

Figure 4. Differences in morphological and ultrastructural properties of cells including (a) area, (b) perimeter, (c) circularization and (d) area normalized actin signal.

GC: Growth Control; AC: Adipogenic Control; AV: Adipogenic Vibration.

Results are presented as mean \pm SD.

${ }^{*} \mathrm{p}<0.05$ between $\mathrm{GC}$ and $\mathrm{AC} ;{ }^{\dagger} \mathrm{p}<0.05$ between $\mathrm{AC}$ and $\mathrm{AV}$.

Table 2. Components of cellular membrane roughness recorded with AFM probing including root-mean-square roughness (Rq), maximum height (Ry) of cell surface, maximum valley depth (Rv) of the cell surface roughness and maximum peak height (Rp).

\begin{tabular}{lllll}
\hline Group & $\mathrm{Rq}(\mathrm{nm})$ & $\mathrm{Ry}(\mathrm{nm})$ & $\mathrm{Rv}(\mathrm{nm})$ & $\mathrm{Rp}(\mathrm{nm})$ \\
\hline $\mathrm{GC}$ & $2.86 \pm 1.46$ & $13.97 \pm 5.74^{*}$ & $-3.22 \pm 2.17$ & $10.75 \pm 3.62^{*}$ \\
AC & $0.65 \pm 0.26$ & $3.71 \pm 1.34^{*}$ & $-1.73 \pm 1.10$ & $1.99 \pm 0.30^{*}$ \\
AV & $0.59 \pm 0.07$ & $3.18 \pm 0.77$ & $-1.47 \pm 0.31$ & $1.71 \pm 0.59$ \\
\hline
\end{tabular}

GC: Growth Control; AC: Adipogenic Control; AV: Adipogenic Vibration; SD: standard deviation; Rq: root-mean-square roughness; Ry: maximum height; Rv: maximum valley depth; Rp: maximum peak height.

Results are presented as mean $\pm \mathrm{SD}$.

${ }^{*} \mathrm{p}<0.05$ between Growth Control and Adipogenic Control groups.

suppression in their expression suggests that LIV suppresses adipogenic commitment and differentiation of bone marrow stem cells.

Application of LIV signals during adipogenic induction also resulted in physical changes in the bone marrow stem cells. Adipogenesis-induced circularization in bone marrow stem cells ${ }^{44}$ was suppressed with LIV signals. Actin network is the main determinant of the shape and structure of cells, and actin remodeling is required for adipogenesis. ${ }^{45}$ The rearrangement and increase in actin provide stability to the cell shape during lipid accumulation. ${ }^{45,46}$ Our previous results showed that LIV application increased total actin content in bone marrow stem cells during quiescence and osteogenic commitment but that increase was homogeneous through the cell. ${ }^{31}$ Here, actin signal for adipogenic cells was mainly observed in cellular periphery but actin signal was lower when the circularization was reduced and fibroblastic shape retained. In addition to actin, ENC-1, an actin binding protein, plays mediatory role in differentiation of fibroblastic preadipocytes to mature adipocytes during cytoskeletal reorganization and consistent with our results, its expression levels are scant in mature adipocytes, ${ }^{47}$ suggesting that stem cells in AC group reached to maturity faster in vitro, while LIV-applied cells were either delayed or reverted to quiescent like characteristics.

In addition to shape and motility, cellular ultrastructure also determines the mechanical properties and stiffness of cells. ${ }^{48,49}$ Bone marrow stem cells decrease their global mechanical stiffness during adipogenesis, ${ }^{49}$ possibly reflecting that reorganization of actin filaments in the cellular periphery is not supported with cortical stress fibers. Our results suggested that despite the increase in peripheral actin signal, cellular cortex was smoother as measured via AFM indicating that 


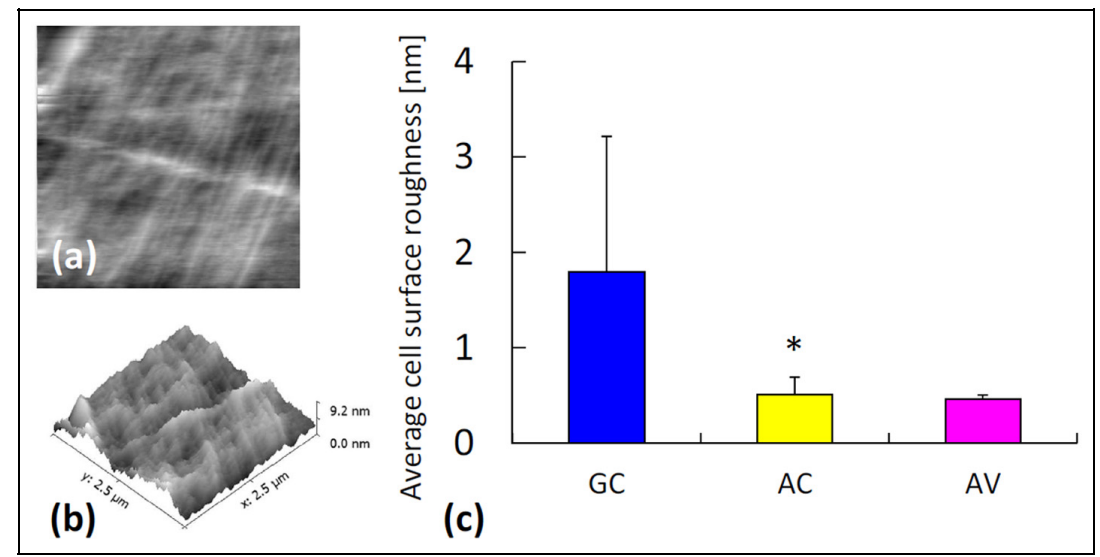

Figure 5. Membrane probing of DI-ORL-UVA cells in culture media using AFM: (a) representative surface map, (b) 3D surface and (c) average cellular membrane roughness.

GC: Growth Control; AC: Adipogenic Control; AV: Adipogenic Vibration.

Results are presented as mean \pm SD.

*p $<0.05$ between GC and AC.

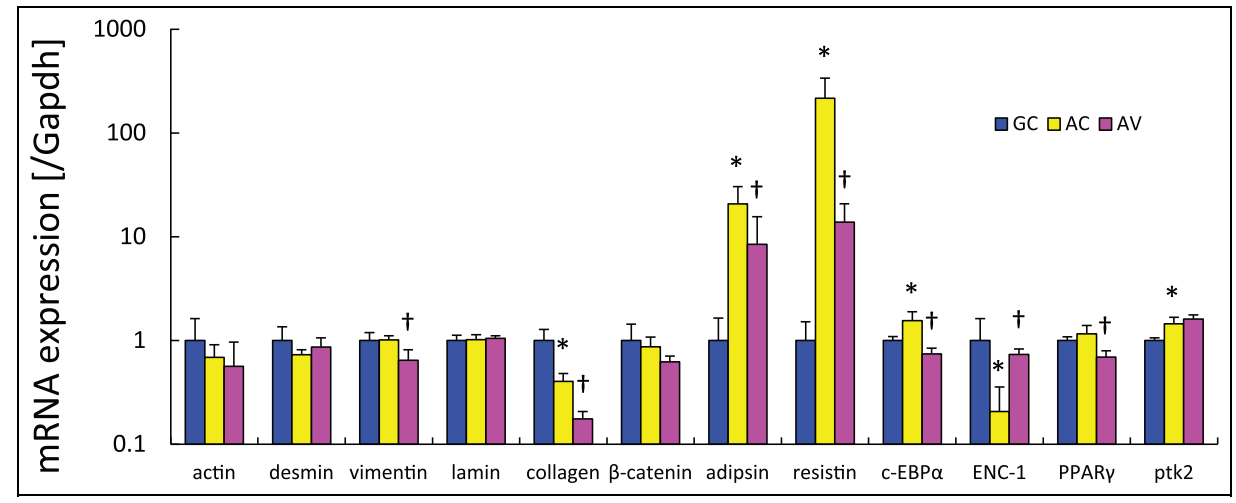

Figure 6. Molecular expression of selected cytoskeletal or adipogenic markers measured by qPCR normalized to house-keeping gene (GAPDH).

GC: Growth Control, AC: Adipogenic Control, AV: Adipogenic Vibration.

Results are presented as mean \pm SD.

*p $<0.05$ between $\mathrm{GC}$ and $\mathrm{AC} ;{ }^{\dagger} \mathrm{p}<0.05$ between $\mathrm{AC}$ and $\mathrm{AV}$.

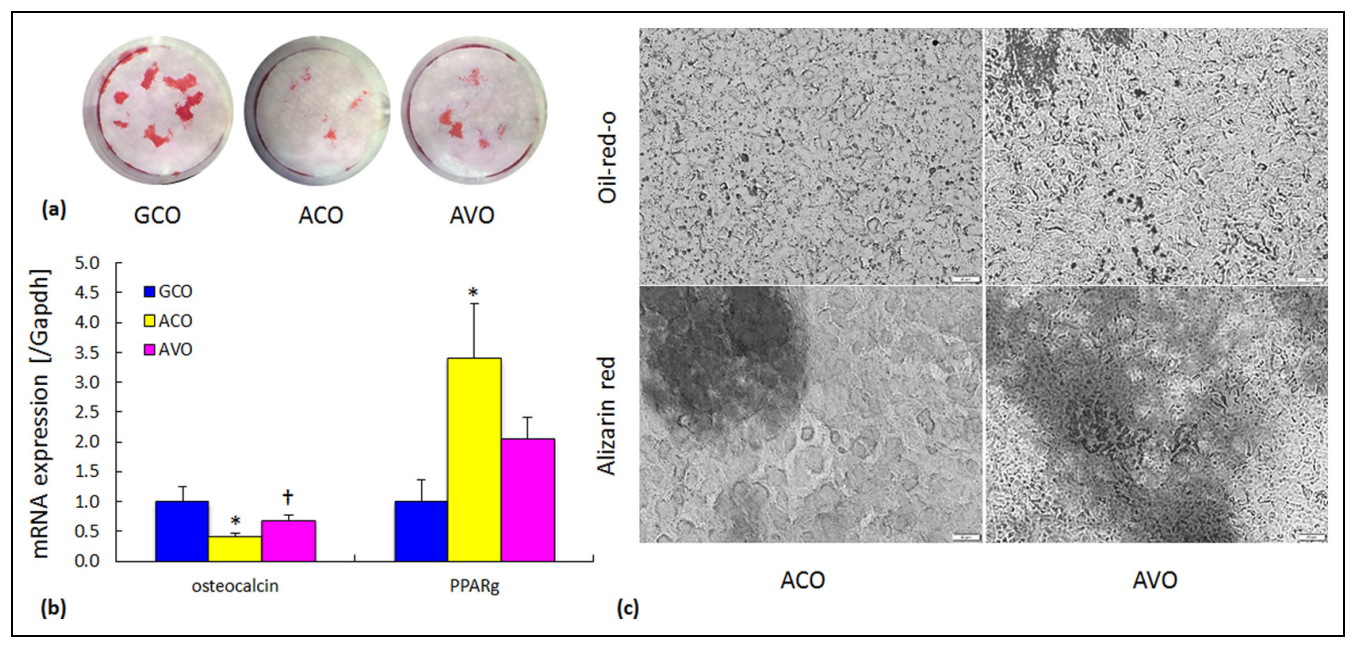

Figure 7. Osteogenic potential of DI-ORL-UVA cells after I week of adipogenic induction: (a) global alizarin red staining, (b) molecular expression of osteocalcin and PPAR $\gamma$ and (c) micrographs from alizarin red and Oil-Red-O stains.

GCO: Growth Control followed by osteogenic induction; ACO: Adipogenic Control followed by osteogenic induction with no adipogenic induction; AVO: Adipogenic Vibration followed by osteogenic induction with no adipogenic induction and vibration.

Results are presented as mean $\pm S D$.

${ }^{*} \mathrm{P}<0.05$ between $\mathrm{GCO}$ and $\mathrm{ACO} ;{ }^{\dagger} \mathrm{P}<0.05$ between $\mathrm{ACO}$ and AVO. 
LIV signals did not induce any change in cortex roughness. Since cells may lose their thicker actin fibers during adipogenic differentiation and form new fibers oriented in a thinner conformation after differentiation, ${ }^{50}$ perhaps, the resolution of AFM was not able to probe these thin filaments.

Cytoskeletal elements are also important modulators of cellular mechanosensitivity, linking regional or global deformations elsewhere in the cell to nuclear processes. ${ }^{51,52}$ Bone marrow mesenchymal stem cells are readily sensitive and responsive to mechanical loads, however pathological conditions such as aging and obesity reduce their mechanosensitivity and therefore bone marrow adipogenesis increases with a reduction in bone mass. ${ }^{18}$ These phenomena are corroborated with degradations in cytoskeletal assembly during aging and adipogenesis, ${ }^{53,54}$ suggesting that bone marrow stem cells may not be able to benefit from LIV signals with high efficacy. Restoration of mechanosensitivity during debilitating conditions may be required to revert and increase osteogenic potential of adipocyte committed mesenchymal stem cells. Improved understanding on the sub-cellular determinants of mechanosensitivity may guide the clinical efforts for the suppression of bone marrow adipogenesis and increase in bone mass during aging and obesity.

\section{Acknowledgements}

The author(s) thank Melis Olcum, Hadi M Zareie, Ozden Yalcin-Ozuysal and Biotechnology and Bioengineering Research and Application Center, Izmir Institute of Technology for expert technical help.

\section{Declaration of conflicting interests}

The author(s) declared no potential conflicts of interest with respect to the research, authorship and/or publication of this article.

\section{Funding}

The author(s) disclosed receipt of the following financial support for the research, authorship, and/or publication of this article: This work was funded by the Scientific and Technological Research Council of Turkey (111T577).

\section{References}

1. Deitel M. Overweight and obesity worldwide now estimated to involve 1.7 billion people. Obes Surg 2003; 13: 329-330.

2. Tanabe Y, Koga M, Saito M, et al. Inhibition of adipocyte differentiation by mechanical stretching through ERK-mediated downregulation of PPAR $y 2 . J$ Cell Sci 2004; 117: 3605-3614.

3. Farooqi IS and O'Rahilly S. Genetic factors in human obesity. Obes Rev 2007; 8(Suppl. 1): 37-40.

4. Bouret S, Levin BE and Ozanne SE. Gene-environment interactions controlling energy and glucose homeostasis and the developmental origins of obesity. Physiol Rev 2015; 95: 47-82.

5. Wright SM and Aronne LJ. Causes of obesity. Abdom Imaging 2012; 37: 730-732.

6. Vitali A, Murano I, Zingaretti MC, et al. The adipose organ of obesity-prone $\mathrm{C} 57 \mathrm{BL} / 6 \mathrm{~J}$ mice is composed of mixed white and brown adipocytes. $J$ Lipid Res 2012; 53: 619-629.

7. Styner M, Thompson WR, Galior K, et al. Bone marrow fat accumulation accelerated by high fat diet is suppressed by exercise. Bone 2014; 64: 39-46.

8. Fazeli PK, Horowitz MC, MacDougald OA, et al. Marrow fat and bone- new perspectives. $J$ Clin Endocrinol Metab 2013; 98: 935-945.

9. Tan SH, Senarath-Yapa K, Chung MT, et al. Wnts produced by Osterix-expressing osteolineage cells regulate their proliferation and differentiation. Proc Natl Acad Sci USA 2014; 111: E5262-E5271.

10. Gautam J, Choudhary D, Khedgikar V, et al. Microarchitectural changes in cancellous bone differ in female and male $\mathrm{C} 57 \mathrm{BL} / 6$ mice with high-fat diet-induced low bone mineral density. Br J Nutr 2014; 111: 1811-1821.

11. Xiao Y, Cui J, Li YX, et al. Dyslipidemic high-fat diet affects adversely bone metabolism in mice associated with impaired antioxidant capacity. Nutrition 2011; 27: 214 220.

12. Hamrick MW, Pennington C, Newton D, et al. Leptin deficiency produces contrasting phenotypes in bones of the limb and spine. Bone 2004; 34: 376-383.

13. Di Iorgi N, Mo AO, Grimm K, et al. Bone acquisition in healthy young females is reciprocally related to marrow adiposity. J Clin Endocrinol Metab 2010; 95: 2977-2982.

14. Qiu W, Andersen TE, Bollerslev J, et al. Patients with high bone mass phenotype exhibit enhanced osteoblast differentiation and inhibition of adipogenesis of human mesenchymal stem cells. J Bone Miner Res 2007; 22: $1720-1731$.

15. Wren TA, Chung SA, Dorey FJ, et al. Bone marrow fat is inversely related to cortical bone in young and old subjects. J Clin Endocrinol Metab 2011; 96: 782-786.

16. Pino AM, Rios S, Astudillo P, et al. Concentration of adipogenic and proinflammatory cytokines in the bone marrow supernatant fluid of osteoporotic women. $J$ Bone Miner Res 2010; 25: 492-498.

17. Köllmer M, Buhrman JS, Zhang Y, et al. Markers are shared between adipogenic and osteogenic differentiated mesenchymal stem cells. J Dev Biol Tissue Eng 5: 18-25.

18. Ozcivici E, Luu YK, Adler B, et al. Mechanical signals as anabolic agents in bone. Nat Rev Rheumatol 2010; 6: $50-59$.

19. Ozcivici E. Effects of spaceflight on cells of bone marrow origin. Turk J Haematol 2013; 30: 1-7.

20. Gao J, Fu S, Zeng Z, et al. Cyclic stretch promotes osteogenesis-related gene expression in osteoblast-like cells through a cofilin-associated mechanism. Mol Med Rep 2016; 14: 218-224.

21. Zhang L, Liu W, Zhao J, et al. Mechanical stress regulates osteogenic differentiation and RANKL/OPG ratio in periodontal ligament stem cells by the Wnt/ $\beta$-catenin pathway. Biochim Biophys Acta 2016; 1860: 2211-2219.

22. Kim KM, Choi YJ, Hwang JH, et al. Shear stress induced by an interstitial level of slow flow increases the 
osteogenic differentiation of mesenchymal stem cells through TAZ activation. PLoS ONE 2014; 9: e92427.

23. Zheng L, Chen L, Chen Y, et al. The effects of fluid shear stress on proliferation and osteogenesis of human periodontal ligament cells. $J$ Biomech 2016; 49: 572-579.

24. Nikukar H, Reid S, Tsimbouri PM, et al. Osteogenesis of mesenchymal stem cells by nanoscale mechanotransduction. ACS Nano 2013; 7: 2758-2767.

25. Pemberton GD, Childs P, Reid S, et al. Nanoscale stimulation of osteoblastogenesis from mesenchymal stem cells: nanotopography and nanokicking. Nanomedicine 2015; 10: $547-560$.

26. Luu YK, Capilla E, Rosen CJ, et al. Mechanical stimulation of mesenchymal stem cell proliferation and differentiation promotes osteogenesis while preventing dietaryinduced obesity. $J$ Bone Miner Res 2009; 24: 50-61.

27. Rubin CT, Capilla E, Luu YK, et al. Adipogenesis is inhibited by brief, daily exposure to high-frequency, extremely low-magnitude mechanical signals. Proc Natl Acad Sci USA 2007; 104: 17879-17884.

28. Olcum M, Baskan O, Karadas O, et al. Application of low intensity mechanical vibrations for bone tissue maintenance and regeneration. Turk J Biol 2016; 40: 300-307.

29. Ozcivici E, Luu YK, Rubin CT, et al. Low-level vibrations retain bone marrow's osteogenic potential and augment recovery of trabecular bone during reambulation. PLoS ONE 2010; 5: e11178.

30. Chan ME, Adler BJ, Green DE, et al. Bone structure and B-cell populations, crippled by obesity, are partially rescued by brief daily exposure to low-magnitude mechanical signals. FASEB J 2012; 26: 4855-4863.

31. Demiray L and Ozcivici E. Bone marrow stem cells adapt to low-magnitude vibrations by altering their cytoskeleton during quiescence and osteogenesis. Turk J Biol 2015; 39: 88-97.

32. Uzer G, Pongkitwitoon S, Ete Chan M, et al. Vibration induced osteogenic commitment of mesenchymal stem cells is enhanced by cytoskeletal remodeling but not fluid shear. J Biomech 2013; 46: 2296-2302.

33. Uzer $\mathrm{G}$, Pongkitwitoon $\mathrm{S}$, Ian $\mathrm{C}$, et al. Gap junctional communication in osteocytes is amplified by low intensity vibrations in vitro. PLoS ONE 2014; 9: e90840.

34. Olcum $M$ and Ozcivici E. Daily application of low magnitude mechanical stimulus inhibits the growth of MDAMB-231 breast cancer cells in vitro. Cancer Cell Int 2014; 14: 102 .

35. Sen B, Xie Z, Case N, et al. Mechanical signal influence on mesenchymal stem cell fate is enhanced by incorporation of refractory periods into the loading regimen. $J$ Biomech 2011; 44: 593-599.

36. Batra NN, Li YJ, Yellowley CE, et al. Effects of shortterm recovery periods on fluid-induced signaling in osteoblastic cells. J Biomech 2005; 38: 1909-1917.

37. Pre D, Ceccarelli G, Gastaldi G, et al. The differentiation of human adipose-derived stem cells (hASCs) into osteoblasts is promoted by low amplitude, high frequency vibration treatment. Bone 2011; 49: 295-303.
38. Sen B, Xie Z, Case N, et al. Mechanical strain inhibits adipogenesis in mesenchymal stem cells by stimulating a durable beta-catenin signal. Endocrinology 2008; 149: 6065-6075.

39. Luu Y, Ozcivici E, Capilla E, et al. Development of dietinduced fatty liver disease in the aging mouse is suppressed by brief daily exposure to low-magnitude mechanical signals. Int J Obes 2009; 34: 401-405.

40. Case N, Thomas J, Xie Z, et al. Mechanical input restrains PPAR 22 expression and action to preserve mesenchymal stem cell multipotentiality. Bone 2013; 52: 454-464.

41. Rosen BS, Cook KS, Yaglom J, et al. Adipsin and complement factor D activity: an immune-related defect in obesity. Science 1989; 244: 1483-1487.

42. Rosen ED and MacDougald OA. Adipocyte differentiation from the inside out. Nat Rev Mol Cell Biol 2006; 7: 885-896.

43. Lowe CE, O'Rahilly S and Rochford JJ. Adipogenesis at a glance. J Cell Sci 2011; 124: 2681-2686.

44. Muruganandan S, Roman A and Sinal C. Adipocyte differentiation of bone marrow-derived mesenchymal stem cells: cross talk with the osteoblastogenic program. Cell Mol Life Sci 2009; 66: 236-253.

45. Yang W, Thein S, Lim CY, et al. Arp2/3 complex regulates adipogenesis by controlling cortical actin remodelling. Biochem J 2014; 464: 179-192.

46. Yang W, Thein S, Wang X, et al. BSCL2/seipin regulates adipogenesis through actin cytoskeleton remodelling. Hum Mol Genet 2014; 23: 502-513.

47. Zhao L, Gregoire F and Sul HS. Transient induction of ENC-1, a Kelch-related actin-binding protein, is required for adipocyte differentiation. $J$ Biol Chem 2000; 275: 16845-16850.

48. Suresh S. Biomechanics and biophysics of cancer cells. Acta Biomater 2007; 3: 413-438.

49. Darling EM, Topel M, Zauscher S, et al. Viscoelastic properties of human mesenchymally-derived stem cells and primary osteoblasts, chondrocytes, and adipocytes. $J$ Biomech 2008; 41: 454-464.

50. McAndrews KM, McGrail DJ, Quach ND, et al. Spatially coordinated changes in intracellular rheology and extracellular force exertion during mesenchymal stem cell differentiation. Phys Biol 2014; 11: 056004.

51. Engler AJ, Sen S, Sweeney HL, et al. Matrix elasticity directs stem cell lineage specification. Cell 2006; 126: 677689.

52. Sen B, Guilluy C, Xie Z, et al. Mechanically induced focal adhesion assembly amplifies anti-adipogenic pathways in mesenchymal stem cells. Stem Cells 2011; 29: $1829-1836$

53. Scaffidi $\mathrm{P}$ and Misteli T. Lamin A-dependent nuclear defects in human aging. Science 2006; 312: 1059-1063.

54. Tong $\mathrm{J}$, Li W, Vidal $\mathrm{C}$, et al. Lamin $\mathrm{A} / \mathrm{C}$ deficiency is associated with fat infiltration of muscle and bone. Mech Ageing Dev 2011; 132: 552-559. 